\title{
A Simple Exercise-to-Play Proposal that would Reduce Games Addiction and Keep Players Healthy
}

\author{
Nael Hirzallah \\ Software Engineering Department \\ Applied Science University \\ Amman, Jordan
}

\begin{abstract}
Games players usually get addicted to video games in general and more specifically to those that are usually played over the internet. These players prefer to stay at home and play games rather than playing sports or outdoor games. This paper presents a proposal that aims to implement a simple way to let video games players exercise in order to play. The proposal targets games where players virtually live inside a certain area such as a forest, city or a war zone. Their aim is to explore the area, capture, kill and avoid being killed by something or someone. A costumed built treadmill acting as a movement capture device is proposed to capture players' commands for movements. These movements include Running, walking, Stopping, and Turning. In that way, the players enjoy exercising as well as playing the game. However, sooner or later, the players get exhausted driving them to exit the game. That way, we believe that such a proposal would keep players healthy, and reduce the chance of addiction.
\end{abstract}

Keywords_Virtual Reality; Gaming; Video Game.

\section{INTRODUCTION}

Computer and video games have come a long way since Space Invaders and Pac Man. Video games are becoming increasingly complex, detailed, and compelling to a growing international audience of players. Today's games are much more interesting, and the technology has advanced to the point where a gamer can become immersed in a multimedia-enabled 'virtual reality' or 'alternate world'. With better graphics, more realistic characters, and greater strategic challenges, it's not surprising that some teens would rather play the latest video game than hang out with friends, play sports, or even watch television. Some games, especially online role playing games, can become a substitute for 'real life', and players can become immersed in the experience of living in an imaginary world. Some gamers report that they play games to escape things like family or personal problems - in a similar way to people who use drugs or alcohol to escape their problems.

Although gaming addiction is not yet officially recognized as a diagnosable disorder by the American Medical Association, there is increasing evidence that people of all ages, especially teens and pre-teens, are facing very real, sometimes severe consequences associated with compulsive use of video and computer games.

Thus, people can become addicted to games. Young gamers have shown similar symptoms to people who have drug or alcohol dependence - an inability to stop playing.
Of course, all gamers are not addicts - many teens can play video games a few hours a week, successfully balancing school activities, grades, friends, and family obligations. But for some, gaming has become an uncontrollable compulsion. Studies [1] estimate that 10 percent to 15 percent of gamers exhibit signs that meet the World Health Organization's criteria for addiction. Just like gambling and other compulsive behaviors, teens can become so enthralled in the fantasy world of gaming that they neglect their family, friends, work, and school. Many children spend hours a day on computers, so much so that computers have become a primary source of entertainment for them, as well as a convenient baby-sitter for parents.

In reference [2] by Ricky Lam, many controversial cases in which addicted players commits suicide, murder, or robbery, caused death to negligence, or skipped school were listed. For instance, case number 2, a seventeen-year-old Daniel Petric murdered his mother and injured his father after they refused to let him play an online game named Halo 3. Also, just a week ago, among the ridiculous calls that people made to Emergency 999 in 2012 which the UK police revealed was a midnight call of a father to a 14 year old son who was ignoring his parents' pleas to switch a video game off and get some sleep [3].

In the following section, we will present few of the symptoms and injuries that addicted gamers usually start developing. Next in section 3, solutions proposed by literature and concerned centers will be presented. Section 4, will cover existing tools offered to players to capture real life movements and interpret them into games commands. Then, the costumed build treadmill will be proposed before we conclude.

\section{SyMPTOMS AND Possible INJURIES}

Addicted gamers usually try to be with the computer as much as possible, and in many cases, such gamers lose their confidence; they cannot involve with the social world in real time and they cannot communicate and compete with other people. When such thing happened, it means that they need video game addiction treatment as soon as possible.

In other words, computer game addiction can be diagnosed with a few easily spotted signs. They include but not restricted to:

- School grades dropping

- Avoiding other commitments in order to be with the computer (wagging school, stopping participation in sport) 
- Not seeing friends

- Not talking to parents/family

- Being on the computer in most or all of your spare time.

- Anxiousness to be with the computer.

- Sleep and memory problems when playing an exciting game for 2 or 3 hours before bed

- Family negligence

Furthermore, when playing video games, as with many activities, you may experience occasional discomfort in your hands, arms, shoulders, neck, or other parts of your body. Symptoms such as these can be associated with painful and sometimes permanently disabling injuries or disorders of the nerves, muscles, tendons, blood vessels, and other parts of the body. These musculoskeletal disorders (MSDs) include carpal tunnel syndrome, tendonitis, tenosynovitis, vibration syndromes, and other conditions. While researchers are not yet able to answer many questions about MSDs, there is general agreement that many factors may be linked to their occurrence, including: medical and physical conditions, stress and how one copes with it, overall health, and how a person positions and uses their body during work and other activities, including playing a video game.

RSI (Repetitive Strain Injury) for instance can be developed from playing games or sitting at the computer too long, or repeating certain movements, eg. clicking a mouse button. For gamers or heavy computer users, it's common to get RSI in the wrist. This results from the tendons in the arm and wrist being overworked, causing the tendons and the tissue covering the tendons to become inflamed and sore. Other overuse problems such as neck pains, tingling in the fingers, black rings in the skin under the eyes and muscular stiffness in the shoulders may also be developed from excessing playing.

To summarize, video games can cause injury and addiction. The following section presents solutions which specialists believe that may deal with the injury and addiction problems.

\section{Possible Solution}

Many of the discussed injuries may be avoided by taking breaks while playing. This helps the player's body to avoid MSDs. Also players must make sure that their positions when playing do not encourage discomfort. Whereas, to avoid addiction problems, we believe that there are three ways to approach this: through parents, through offering alternatives, and through exercising to play.

\section{A. Parents'supervision}

Increase parental supervision and parental control may help in avoiding games addictions. Some Consoles like the PS3, Xbox360, Wii, and the PSP have parental control. Parental supervision and control can also be in the form of setting boundaries as to how long the child can be playing games/chatting on the computer. Furthermore, it is suggested that rewarding children with computer time for doing something, like completing an assignment, would make them feel like no one is trying to 'stop' them from using the computer as such, and thus helps.

\section{B. Finding alternatives:}

There are many alternatives to computer games and computers in general for entertainment. They include:

- Playing a sport with friends

- Going out often

- Eating at a restaurant

- Getting involved with a local recreational group

- Drawing

\section{Exercising while playing}

So far, exercising while playing has been presented to the gamers as a way to increase the joy when playing, such as in MSE Weibull Virtual Theater. Giving gamers a feeling of the real world through virtual reality is an exciting challenge. Another reason for exercising while playing is to practice and improve certain physical skills of the player, such as in Tacx. Both examples will be addressed later. Regardless whether the reason for exercising is to enjoy the game more, or to improve certain physical skills, or to get the chance to play if one is prevented from playing by parents or self-control, players sooner or later will get exhausted, and consequently quit playing for the day. These three different reasons could be classified under playing while exercising, exercising while playing, and exercising to play.

As long as players do exercise, addition will not be of a concern. In what follows, we will give a history to the introduction of body interaction in games, and then we will present some recent tools or controllers that are used to interpret and perceive body motions. In section ??, we will propose our vision to a tool that could be used to reduce games addiction by exercising to play, before we state our conclusion.

\section{History to Body InTERACTIONS IN GAMES}

In 1996, Mandala Gesture Xtreme (GX) System [4] became the first commercial arcade application using computer vision. Instead of a projector, the system used a large CRT display, which changed the player's experience where the player could move with more confidence. In 2001, Intel®PlayTM Me2Cam Virtual Game System [5] was the first home product released. At the time, when an average PC screen was a 15" CRT display, it was difficult to play, due to the small screen size. It was hard to see the action on the screen. The recent commercial success of Sony PlayStation Eyetoy [6] and Nintendo Wii [7], which are not a "proper" full body interactive game, introduced the idea of a computer body interaction, full body interaction, and physically interactive games, i.e. games where the main interaction device is a user's body. The user's action was finally moved to take place in front of a large screen (i.e. TV display), where there was more space available for the physical gameplay.

Early design projects in full body interaction games such as those in [8] [9] presented principals for game design. Labanotation has been used in the interaction design context to evaluate Eyetoy Sony PlayStation games [10] and it provided a valuable foundation for the design of movement based interaction. Work of QuiQui Giant Bounce [11] and Kick Ass 
Kung-fu [12] focused around transforming the user movement into the gameplay.

Fairly new types of games called massively multiplayer online role-playing game, (MMORPG), have recently been developed and became very popular in a short time. A very large number of players interact with one another within a virtual game world. Players assume the role of a character (often in a fantasy world) and take control over many of that character's actions. MMORPGs are distinguished by the number of its players, and by the game's persistent world which continues to exist and evolve while the player is offline and away from the game. Worldwide revenues for MMORPGs exceeded half a billion dollars in 2005,[14] and Western revenues exceeded US\$1 billion in 2006, [15]. In 2008, Western consumer spending on subscription MMOGs grew to $\$ 1.4$ billion [16]. World of Warcraft, a popular MMORPG, has more than 10 million subscribers as of February 2012.[17] Star Wars: The Old Republic, released in 2011, became the world's 'Fastest-Growing MMO Ever' after gaining 1 million subscribers within the first three days of its launch[18,19].

In these games, the movement commands, which are walking and running, as well as in other similar games such as Runescape, Tibia, Call of duty, assassin's creed, Starcraft, Prius Online, Gears of War, Second Life, Legend of Mir, Halo, and Everquest, are controlled via one of the following methods:

- A Mouse click on destination position in an overview map, such as in Runescape and World of Warcraft

- A Keystroke or a joystick to indicate forward, backward, left and right directions to move, such as in Call of Duty, Hello, and Assasin's creed.

Although, a small background application can be developed to convert one approach to another, the paper's proposal works with only the second approach in which keystrokes or joysticks commands dictates the moving direction of the virtual player within the game.

\section{OfF SHELF AND SPECIAL CONTROLLERS FOR MOTION CAPTURE}

In this section, we will introduce the most popular off shelf motion controllers that could be used for playing at home. PlayStation Move is a motion-sensing game controller platform for the PlayStation 3 (PS3) video game console by Sony Computer Entertainment (SCE). Based around a handheld motion controller wand, PlayStation Move uses the PlayStation Eye camera to track the wand's position, and inertial sensors in the wand to detect its motion. It was first revealed on 2 June 2009, [20]. Kinect is another controller but designed for Xbox 360. Kinect is a motion sensing input device by Microsoft for the Xbox 360 video game console and Windows PCs. Based around a webcam-style add-on peripheral for the Xbox 360 console, it enables users to control and interact with the Xbox 360 without the need to touch a game controller, through a natural user interface using gestures and spoken commands, [21]. It was aimed at broadening the Xbox 360's audience beyond its typical gamer base. It gives the experience of a controller-free gaming that involves a full body play.
Wii MotionPlus was developed by Nintendo in collaboration with game development tool company AiLive, [22]. The device incorporates a dual-axis [23] tuning fork gyroscope, [24] and a single-axis gyroscope which can determine rotational motion. The information captured by the angular rate sensor can then be used to distinguish true linear motion from the accelerometer readings. This allows for the capture of more complex movements.

In a different setup, MSE Weibull [26] offers system solutions within the sectors of production, test and training in civilian and military markets. The Virtual Theatre and the Omnidirectional treadmill link between the Live and Virtual domains. The Virtual Theatre from MSE is based on an omnidirectional floor, Figure 1.

It was shown to the public at ITEC 2011 for the first time. It facilitates omnidirectional unrestricted walking in the infinite virtual environment, within a finite real world footprint. The increased immersion is claimed to lead to a giant leap towards convergence of the real and the virtual world has been taken.

The WIZDISH ${ }^{\mathrm{TM}}$ locomotion platform, [27], is another controller similar to a treadmill but with no moving parts. It offers the navigation for Virtual Reality and Immersive Worlds. The users experienced when using wizdish [27] is claimed to be similar to a regular treadmill. The player stands on a slick concave disk, as shown in Figure 2, which minimizes friction under foot so the player can shuffle along in place, pretending to walk around.

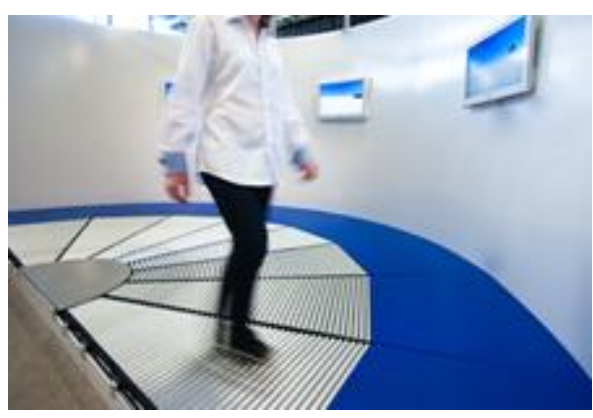

Fig. 1. Mse Weibull Omnidirectional Treadmill

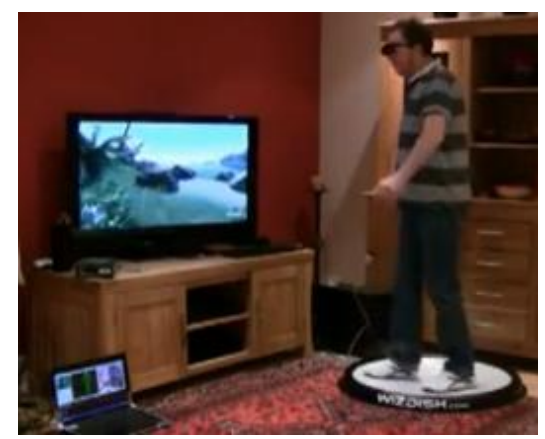

Fig. 2. WIZDISH

Although, all these controller or approaches may come close to satisfy our objective, which is to reduce games addiction, but not exactly. Players would stop playing their session once they get bored and not once they get tired. Thus, this may prevent them from using these controllers again. Our 
proposal aims to get players to sweat while playing. If one puts more efforts in each move, then the outcome would be different and shorter durations per session would make players get tired and have better chance to get back and use the same setup when play again.

Figure 3 shows another setup where players put greater efforts in the moves.

Tacx has created a video game to link cycling around the world and to offer a way to exercise at any time regardless to the weather situation. Tacx' has become a household name for cyclists all over the world. They offered their customers Virtual Reality trainers through software programs and cycling films a unique experience in virtual worlds. They connect the bicycle to a rotation speed sensor as well as sensors for the left and right turnings. The cyclist then rides and starts playing or exercising. However, the main objective behind this is to exercise rather than play.

Finally, the closest to our proposal is Gamerunner [28]. It was an attempt to exhaust the player using a treadmill as a controller which was made available in February 2011. It was yet another way to blend exercise and gaming. As seen in the Figure 4, it was mounted by a joystick to control moving directions and other gamming tools. The Gamerunner is a person-powered treadmill that features 17 buttons and a handlebar that can be turned for looking or moving.

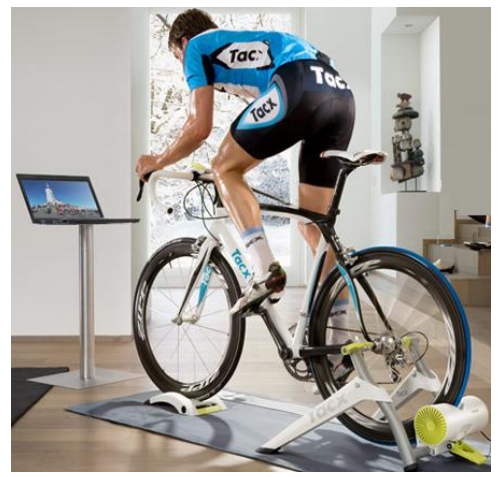

Fig. 3. Tacx Virtual Reality Cycling

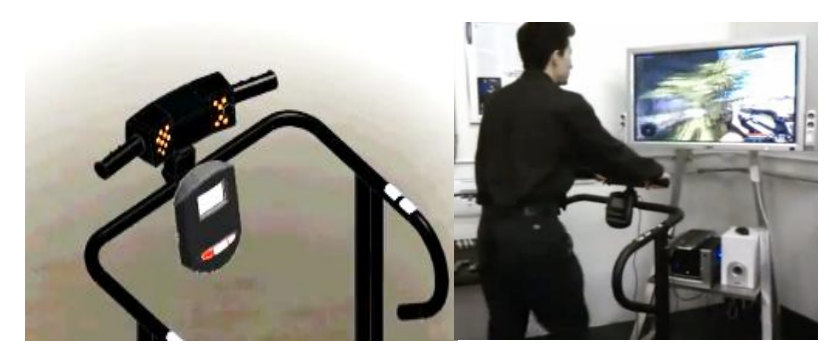

Fig. 4. Gamerunner

\section{PROPOSAL}

This paper proposes a controller that adopts the idea of exhausting the player while playing a video game to avoid long playing sessions; hence, neither reaching a state where the player may start feeling bored, nor playing for long which may lead to addiction.
We believe the presented earlier GameRunner is a good choice; however, keeping the players' hands on the mounted handler all the time, is something that is not preferred by players. This would unfortunately reduce the feeling of excitement when playing the game; thus giving players more reasons for not getting back to the same setup when playing again.

Considering the Call of Duty game, for instance, this paper proposes modifications to the GameRunner in order to give the player more of a feeling to the convergence of the real and the virtual worlds. Keeping in mind that the player may sweat while playing, the addiction becomes of a no concern when playing video games.

The primary modification proposed is to make the fixed handler portable, or at least to split it into two pieces: one that is portable and another that is fixed. The portable handler could be in the form of a wireless joystick or fake machine gun (in case of a FPS, First Person Shooter, game) that includes few buttons which are responsible for the most frequent commands, such as Fire, Crouch, Stand, prone, and Jump as well as Looking left or right. That way, the player will have his/her hands off the treadmill and on the device that may resemble the virtual device being carried in the game.

The proposal classifies the commands offered by the game into three: Frequent, Motion based, and Optional. It distributes these commands over three devices. The frequent commands, such as those mentioned earlier, will be placed on the portable handler (or machine gun). The treadmill will include the motion based commands, such as Running, walking, and moving left or right. While the optional (or least used) commands such as Equipment and Inventory will be placed on the fixed handler, or added to the portable handler, if fixed handler is chosen not to exist. Moreover, the treadmill speed triggers, such as to increase or reduce as well as to come to a gradual full stop will be added to the frequent commands.

To implement the four Motion-based commands on the treadmill, namely: Running, Walking, and Moving left or right, first the rotation sensor similar to that used by Tacx will be used to indicate Running and walking.

This will basically translate the motor speed to the appropriate command based on a preset threshold. Second, for moving right and left, two concave slim switches are installed beneath the front sides of the rotating belt of the treadmill: one under the right-front, and another under the left-front corners, as shown in the Figure 5. Once a player steps on the center of any of these two switches, it will indicate moving left or right.

Each right or left switch press will represent a number of keystrokes used to control left or right movements depending on its sequence number, up to a specific maximum value. If the maximum is four, for instance, then the first step on a switch will represent one keystroke; the second will represent two keystrokes, and so on till either the switch is not stepped on it for some time that is long enough to break the sequence or a maximum of four keystrokes is reached. Breaking the sequence will result in the sequence reset. 


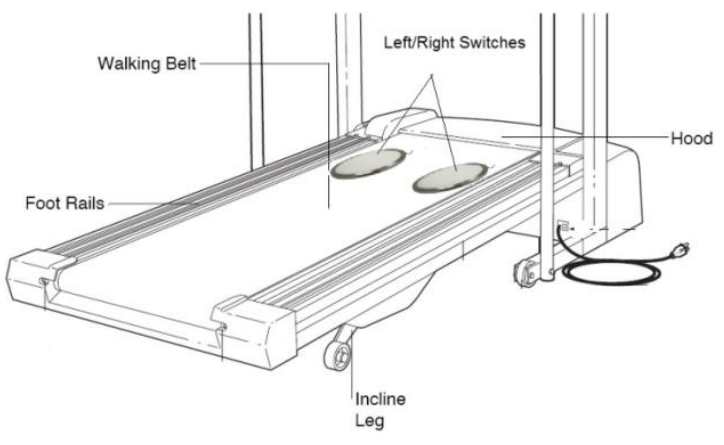

Fig. 5. Similar to Gamerunner but with portable Handler

The portable handler, in turn, is similar to a wireless keyboard providing the needed keystrokes to represent both frequent and optional commands (which also could include the right and left moving buttons, as alternatives to stepping on the switches). For the mouse pointer, which is used to look left or right, there are many ways to connect the portable handler with a wireless Motion sensing air mouse, such as Measy RC11 [29] or Flymouse Mouse [30]. We could also provide a webcam and object motion tracker software to detect motion produced by the head of the player or the tip of the portable handler. One example of such software that is available as a freeware is Camera Mouse 2013 [31]. A snapshot of the software settings is shown in Figure 6. That way, if the player turns his/her head left, the mouse will follow which consequently will be perceived as a look-left command in the Call of Duty game.

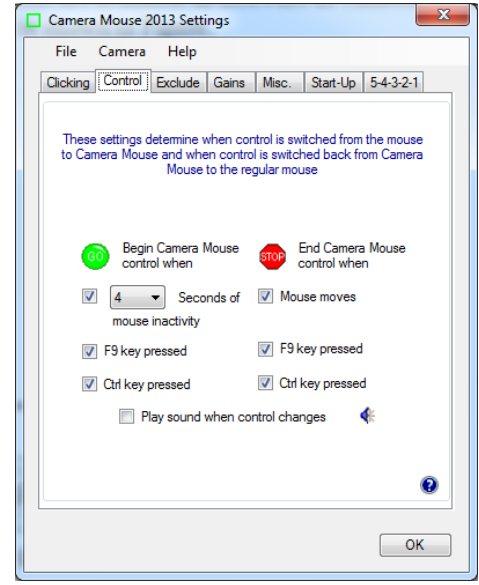

Fig. 6. Camera Mouse 2013 setting screen shot

\section{CONCLUSION}

The paper has discussed the issue of games addiction that many players may be suffering from. Such a phenomenon has recently been bubbling up to the surface and becoming the concern of not only parents but also the society. The paper presented the symptoms that may appear on people who may be addicted to games or are becoming ones, as well as the possible injuries. The paper then drives the readers towards discussing possible solutions to avoid such a problem. It then focuses on one of these possible solutions by presenting the available tools and devices that could be used within the solution category. After discussing the drawback of them, it proposes one that is believed to have overcome most of these drawbacks, except one. The proposal of this paper suffers from the same problem that most of the other pieces of gaming exercise equipment have suffered: its size. With the advent of more family friendly consoles, like the 360 , that problem would grow. However, self or parental control would then be necessary to offer such a proposal as a way to allow players to play without imposing any time control, yet with the confidence that such a setup will lead to no addiction.

\section{ACKNOWLEDGMENT}

The author would like to acknowledge the financial support received from Applied Science University that helped in accomplishing the work of this article. He also would like to acknowledge the time and feedback provided by his son, Adam, who has helped him in verifying many of the issues as well as the feasibility concerning the proposal.

\section{REFERENCES}

[1] http://www.video-game-addiction.org/

[2] http://listverse.com/2010/11/07/top-10-cases-of-extreme-gameaddiction/

[3] "999? My son won't go to bed: Police reveal the ridiculous calls people make to emergency number" MailOnline Newsletter, Wednesday, Dec 262012

[4] Mandala Gesture Xtreme (GX) System [Hardware] (1996) Vivid Group Toronto, Canada

[5] Intel ${ }^{\circledR}$ Play ${ }^{\mathrm{TM}} \mathrm{Me2Cam*}$ Virtual Game System [Software] (2001) Intel, St Clara, CA, USA

[6] Eyetoy [Hardware] (2005) Sony Corporation In: Eyetoy. Available at www.eyetoy.com, Accessed 20 Sep 2008

[7] Nintendo Wii [Hardware] (2007) Nintendo In: Nintendo. Available at www.nintendo.co.uk/NOE/en_GB/systems/about_wii_1069.html. Accessed 20 Sep 2008

[8] D'Hooge H, Goldsmith M (2001) Game Design Principles for the Intel® Play ${ }^{\mathrm{TM}}$ Me2Cam* Virtual Game System. Intel Technology Journal 2001/4. pp. 1-9.

[9] Warren J (2003) Unencumbered Full Body Interaction in Video Games. In: Parsons School of Design. Available at http://a.parsons.edu/ jonah/jonah_thesis.pdf. Accessed 2 Nov 2009

[10] Loke L, Larssen AT, Robertson T, Edwards J (2007) Understanding movement for interaction design: frameworks and approaches. Pers Ubiquit Comput, 11/8. pp 691-701. doi:10.1007/s00779-006-0132-1

[11] QuiQui's Giant Bounce [Software] (2003). Höysniemi J, Hämäläinen P In: University of Tampere. Available at www.cs.uta.fi/kukakumma. Accessed 2 Nov 2009

[12] Kick Ass Kung-Fu [Artwork] (2006) Hämäläinen P In: Kick Ass KungFu. Available at www.kickasskungfu.net. Accessed 2 Nov 2009

[13] Liu CC, Chiou WC, Tai SJ, Tsai CC, Chen GD, Jong CW et al (2006) Wristbands as Interaction Devices: a Vision-Based Interaction Space for Facilitating Full-Body Learning. 4th IEEE International Workshop on Wireless, Mobile and Ubiquitous Technology in Education, (WMUTE 2006), Greece. pp. 171-173. doi:10.1109/WMTE.2006.261370

[14] Parks Associates (2005). "Online Gaming Revenues to Triple by 2009". Retrieved 2007-05-02.

[15] Harding-Rolls, Piers (PDF). Western World MMOG Market: 2006 Review and Forecasts to 2011. London, UK: Screen Digest. Archived from the original on 2007-06-04. Retrieved 2007-05-17.

[16] Harding-Rolls, Piers (PDF). Subscription MMOGs: Life Beyond World of Warcraft. London, UK: Screen Digest. Archived from the original on 2009-12-25. Retrieved 2009-03-30.

[17] "Activision Blizzard Announces Record Fourth Quarter and Calendar Year 2011 Earnings". Activision Blizzard.

[18] "Star Wars: The Old Republic Jumps to Light Speed (NASDAQ:EA)". Investor.ea.com. 2011-12-23. Retrieved 2012-04-11.

[19] Rundle, Michael (2011-12-27). "Star Wars: The Old Republic Is 'Fastest-Growing MMO Ever' With 1m Users". Huffington Post. 
[20] "Sony Computer Entertainment America announces an unparalleled software line up, launch of the PSP go system, and new services for PSP (PlayStation Portable) and PlayStation Network at E3 2009". Sony Computer Entertainment. 2009-06-02. http://www.scei.co.jp/corporate/release/090603c_e.html. Retrieved 2009-06-03.

[21] "Project Natal" 101". Microsoft. June 1, 2009. Archived from the original on June $1, \quad 2009$. http://blog.seattlepi.com/digitaljoystick/archives/169993.asp. Retrieved June 2, 2009.

[22] "AILive Reveals LiveMove2 For Wii MotionPlus". Gamasutra.com. July $15,2008.2 \quad$ http://www.gamasutra.com/phpbin/news_index.php?story=19432. Retrieved December 12, 2012.

[23] "INVENSENSE IDG-600 MOTION SENSING SOLUTION SHOWCASED IN NINTENDO'S NEW Wii MotionPlus ACCESSORY".

http://invensense.com/mems/gyro/documents/articles/071508.html.

Retrieved December 12, 2012.
[24] "MEMS Gyroscope Technology". InvenSense. Archived from the $\begin{array}{llll}\text { original on } & \text { April } & \end{array}$ http://web.archive.org/web/20080416215417/

http://www.invensense.com/company/technology.html. Retrieved Dec. $12,2012$.

[25] M. Zyda et al., "From Viz-Sim to VR to Games: How We Built a Hit Game-Based Simulation," Organizational Simulation: From Modeling \& Simulation to Games \& Entertainment, W.B. Rouse and K.R. Boff, eds., Wiley Press, 2005, pp. 553-590.

[26] http://www.mseab.se/ Retrieved 2012-06-03

[27] www.wizdish.com Retrieved 2013-01-03

[28] http://www.gamerunner.us/ Retrieved 2012-07-06

[29] http://www.measy.com.cn/product/showproduct48_en.htm Retrieved 2012-06-03

[30] http://www.airflymouse.com/air-mouse/air-mouse-iii.html Retrieved 2012-06-03

[31] http://www.cameramouse.org/ Retrieved 2011-09-20 